\title{
A APLICAÇÃO DO INSTITUTO DA MULTIPARENTALIDADE E SEUS ASPECTOS PROBLEMÁTICOS: FILIAÇÃO SÓCIO-AFETIVA E DIVÓRCIO
}

\author{
Thiago Augusto Galeão de Azevedo ${ }^{1}$
}

\section{RESUMO}

O presente artigo tem como objeto de estudo o instituto da Multiparentalidade, sua aplicação e seus aspectos problemáticos. Através da metodologia Pesquisa Bibliográfica, pretende-se responder à pergunta: em que medida o ex-cônjuge, que teria uma relação de afeto, ao ponto de poder ser caracterizada ctomo sócio-afetiva, para com o filho de sua ex-esposa ou exmarido, teria a legitimidade de ter reconhecido o instituto da multiparentalidade, podendo ingerir na vida dessa criança? Para tanto, analisar-se-á os fundamentos jurídicos do instituto da multiparentalidade e o entendimento jurisprudencial sobre este, averiguando-se, por fim, a possibilidade de sua aplicação diante do panorama fático proposto.

Palavras-chave: Multiparentalidade; Afetividade; Divórcio; Igualdade; Família.

\section{THE APPLICATION OF THE INSTITUTE OF MULTIPARENTALITY AND ITS PROBLEMATIC ASPECTS: SOCIO-AFFECTIVE MEMBERSHIP AND DIVORCE}

\begin{abstract}
The present article has as object of study the Multiparentality, its application and its problematic aspects. Through the Bibliographic Research methodology, the question is asked: to what extent does the ex-spouse, who would have a relationship of affection, to the point of being characterized as affective partner, to the son of his ex-partner, would have the legitimacy of having recognized the multiparentality, can ingest in the life of this child? It will analyze the legal foundations of the multiparentality and the jurisprudential understanding of it, and, finally, investigate the possibility of its application in the face of the proposed scenario.
\end{abstract}

Keywords: Multiparentality; Affectivity; Divorce; Equality; Family.

\section{INTRODUÇÃO}

\footnotetext{
${ }^{1}$ Doutorando em Direito pela Universidade de Brasília (UNB). Mestre em Direito, Políticas Públicas e Desenvolvimento Regional pelo Centro Universitário do Estado do Pará (CESUPA). Especialista em Direito Civil pela Pontifícia Universidade Católica de Minas Gerais (PUC MG). Professor Universitário. Advogado. Endereço Postal: Rua João Balbi, 753, apt. 301, CEP 66055-280, Belém-PA. E-mail: thiagogaleao@hotmail.com.
}

Revista de Direito de Família e Sucessão | e-ISSN: 2526-0227 | Maranhão | v. 3 | n. 2 | p. 17 - 35 | Jul/Dez. 2017. 
O presente ensaio tem como objeto de estudo o instituto da multiparentalidade, sua aplicação e seus aspectos problemáticos. Em linhas mais específicas, o presente estudo visa analisar a possibilidade de se aplicar o citado instituto jurídico em situações marcadas por uma relação sócio-afetiva, seguida de um divórcio. Explicar-se-á.

Pensemos em uma situação hipotética. Uma criança com vínculo familiar em relação a seus dois pais biológicos. Suponhamos que estes se divorciem e um dos pais comece a se relacionar com outra pessoa, casando-se com esta ou mesmo em União Estável. A título didático, consideremos que houve um segundo casamento. Este cônjuge(a) passa a construir laços afetivos com a criança, ao ponto de construir uma relação sócio-afetiva com a mesma.

Até então, considerando o citado panorama hipotético, extrai-se a presença de quatro indivíduos: os dois pais biológicos da criança, que possuem uma relação marcada por atenção e presença em relação à mesma; o(a) cônjuge e a própria criança. A discussão proposta pelo presente artigo passa a ganhar corpo e sentido se pensarmos na ocorrência de divórcio de um dos pais da criança para com o seu ex-cônjuge, restando, assim, os vínculos biológicos com a criança (que não seriam afetados), mas também o vínculo sócio-afetivo do ex-cônjuge, que possui um relacionamento e afeto com a criança em um período de tempo razoável para tanto.

Eis o objeto do presente artigo, através do qual se pretende responder a perguntaproblema: em que medida é cabível a aplicação do instituto da Multiparentalidade em casos marcados por uma relação sócio-afetiva, seguida de um divórcio? Em outras palavras, o excônjuge, que teria uma relação de afeto, ao ponto de poder ser caracterizada como sócioafetiva, para com o filho de sua ex-esposa ou ex-marido, teria a legitimidade de ter reconhecido o instituto da multiparentalidade a seu favor, podendo ingerir na vida dessa criança?

Para a realização da análise do panorama jurídico proposto, o presente artigo está estruturado em duas seções. Inicialmente, realizar-se-á um estudo dos fundamentos jurídicos do instituto da Multiparentalidade, perpassando por temáticas como a Constitucionalização do Direito Civil, Princípio da Afetividade e da Pluralidade das Entidades Familiares, chegando-se à análise da Multiparentalidade e seus efeitos em relação aos laços biológicos e sócio-afetivos.

Revista de Direito de Família e Sucessão | e-ISSN: 2526-0227 | Maranhão | v. 3 | n. 2 | p. 17 - 35 | Jul/Dez. 2017. 
Em uma segunda seção, passar-se-á a analisar a possibilidade ou não do reconhecimento do instituto da Multiparentalidade em casos marcados pelas questões trazidas acima, quais sejam: relação sócio-afetiva seguida de um divórcio.

\section{O INSTITUTO DA MULTIPARENTALIDADE E SEUS FUNDAMENTOS JURÍDICOS}

Na presente seção, analisar-se-á os principais institutos e argumentos jurídicos que possuem relação com o panorama jurídico citado anteriormente. Tem-se como objetivo investigar a situação apresentada, a partir dos principais fundamentos jurídicos atinentes ao tema, assim como à luz da jurisprudência nacional; para que se possa chegar à melhor resposta à problemática apresentada.

\subsection{A CONSTITUCIONALIZAÇÃO DO DIREITO CIVIL}

Para a análise da problemática apresentada, entende-se primordial, inicialmente, tecer considerações acerca do fenômeno da Constitucionalização do Direito Civil, isto porque o Direito de Família, ramo do Direito Civil no qual o caso está majoritariamente situado, não está mais ligado à sua concepção tradicional.

Concepção tradicional esta nitidamente influenciada pelo Código de Napoleão, séc. XIX, que era pensado a partir da concepção de autonomia do Direito Civil, das relações privadas, que estariam isoladas da intervenção do Estado, do Poder Público. Sobre o Direito Civil Tradicional, destaca-se o sustentado por Cardoso (2016, p.3):

A formação do Direito Civil tradicional brasileiro foi influenciada pelo paradigma moderno e sua busca incessante por determinação. Escondido atrás do método das ciências duras e com foco na segurança, fez da clareza, coerência e completude seu mapa de aplicação. Logo, ignorou uma série de questões referentes aos seres humanos envolvidos, em cumprimento das normas preestabelecidas e às vezes, pela opção ideológica que escolhia o

Revista de Direito de Família e Sucessão | e-ISSN: 2526-0227 | Maranhão | v. 3 | n. 2 | p. 17 - 35 | Jul/Dez. 2017. 
discurso que entenderia qual norma seria considerada preestabelecida. De fato, a realidade social codificadora em 1916 esteve completamente afastada da concretude e fática que a suportaria.

Um Direito Civil autônomo que pode ser vislumbrado, claramente, no Código Civil de 1916, documento este essencialmente patriarcal, liberal e patrimonialista. Marcado pela absoluta autonomia da vontade dos indivíduos. Os institutos fundamentais do Direito Civil, como contrato, propriedade e família, estavam tutelados tão somente no referido código, que se dizia o responsável exclusivamente por sua tutela, devido à citada autonomia do Direito Civil, a sua autossuficiência (VENOSA, 2015).

Todavia, o Direito de Família não deve mais ser analisado à luz de tal concepção tradicional, uma vez que com a vigência da Constituição de 1988, muito bem definida pelo termo “Constituição Cidadã”, e do Código Civil de 2002, inúmeros princípios e normas marcadas por valores solidários passaram a permear o Direito Civil.

Trata-se de uma transição paradigmática valorativa, visto que no panorama do Direito Civil Tradicional se dava prevalência ao ter, por isso à propriedade e ao que estava consubstanciado em contrato; com a incidência dos citados princípios e normas, o ser passou a assumir um papel de protagonista, prevalecendo valores como dignidade da pessoa humana e solidariedade.

No que concerne ao princípio da dignidade da pessoa humana, pode-se relacioná-lo à proteção constitucional dada à família não constituída através do casamento (art. 226, §3 CF), assim como à família monoparental (artigo 226, $\S 4^{\circ} \mathrm{CF}$ ), à liberdade de escolha quanto a estrutura familiar, desde que à luz do princípio da paternidade responsável e à luz da proteção contra a violência doméstica no âmbito familiar, protegendo os seus integrantes (artigo 226, § $8^{\circ} \mathrm{CF}$ ). Assim, a dignidade da pessoa humana influencia em várias esferas da proteção do direitos próprios ao instituto da família (GONÇALVES, 2011).

oç A Constituição Federal de 1988, nitidamente, representa um marco para o Direito Civil, uma vez que aquela assume institutos que se diziam exclusivos das relações privadas, do Direito Civil, como propriedade, família e contratos. Assim, o Direito Civil passa a ser permeado por normas e princípios constitucionais. O texto constitucional passou a demarcar 
os limites da autonomia privada, da propriedade, do controle de bens, da proteção do núcleo familiar.

Há, portanto, a constitucionalização do Direito Civil, um Direito Civil Constitucional. A propriedade, até então elemento que tinha um papel fundamental no Código Civil de 1916, assume um papel secundário, cedendo espaço para a dignidade da pessoa humana (VENOSA, 2015).

Neste novo panorama, destacam-se dois princípios de suma importância na CF/88, trata-se do princípio da igualdade, este entendido em sua concepção substancial (art. $5^{\circ} \mathrm{CF}$ ) e o princípio da solidariedade social (previsto no art. $3^{\circ}$, I, da CF). Dois dos principais princípios que irradiam as relações privadas, inclusive, as relações familiares.

No âmbito do Direito de Família, a citada transição paradigmática se faz evidente quando analisado o art. 226 da CF/88, onde fica consubstanciado, principalmente, um valor: a inclusão. Família não é mais aquela advinda, exclusivamente, do casamento. Incluem-se neste conceito outras formações, como as formadas através do afeto. Neste sentido, destaca-se o que preleciona Cristiano Farias e Nelson Rosenvald (2016, p. 73, grifo do autor):

Em última análise, é possível afirmar: todo e qualquer núcleo familiar merece especial proteção do Estado, a partir da cláusula geral de inclusão constitucional. Equivale a dizer: todas as entidades formadas por pessoas humanas que estão vinculadas pelo laço afetivo, tendendo à permanência, estão tuteladas juridicamente pelo Direito das Famílias, independentemente de celebração de casamento. É o que vem se denominando família eudemonista, isto é, tendente à felicidade individual de seus membros, a partir da convivência, permitindo que cada pessoa se realize, pessoal e profissionalmente, convertendo-se em seres socialmente úteis, não mais se confinando ao estreito espaço da sua própria família.

A partir do citado excerto, pode-se destacar que a valorização do afeto nas relações familiares está nitidamente relacionada ao fenômeno da Constitucionalização do Direito Civil. Ao ponto em quese deva promover a inclusão no âmbito familiar, reconhecendo-se formas de vida, laços de afeto, mesmo que estes não se encaixem no padrão do casamento. 
Para aprofundar a discussão sobre o assunto, analisar-se-á o princípio da afetividade na próxima seção, este como um produto de um fenômeno maior, a Constitucionalização do Direito Civil.

\subsubsection{Princípio da Afetividade e da Pluralidade das Entidades Familiares: o reconhecimento da filiação Sócio-afetiva.}

A partir do que foi analisado na seção anterior, destaca-se que a importância do afeto nas relações privadas é um produto de um panorama construído a partir da Constitucionalização do Direito Civil, da valorização da dignidade da pessoa humana.

O princípio da afetividade, apesar de não possuir previsão expressa na Constituição Federal, possui fundamento constitucional, com base nas noções de dignidade da pessoa humana (art. $1^{\circ}$, III, CF/1988), de solidariedade social (art. $3^{\circ}, \mathrm{I}, \mathrm{CF} / 1988$ ) e de igualdade entre os filhos (art. 5, caput, e 227, $\S 6^{\circ}$, da CF/1988), todos princípios constitucionais (TARTUCE, 2017).

Diante do contexto alcançado, permeado por noções como solidariedade, dignidade e igualdade, tornou-se insuficiente ignorar a qualidade das relações familiares em prol de um simples laço genético. Explica-se. Com a valorização da dignidade da pessoa humana, tornase inadequado considerar as relações familiares apenas em seu caráter objetivo, biológico. As relações entre indivíduos em uma determinada sociedade, claramente, é mais complexa de que um simples resultado de exame de DNA, que atesta a paternidade, por exemplo.

Assim, passou-se a considerar a qualidade das relações sociais, entre elas as familiares, para fins de efeitos jurídicos, uma vez que é na qualidade da relação contraída entre sujeitos que valores como dignidade e solidariedade podem ser auferidos, como respeitados ou não.

A consideração do afeto nas relações familiares exerceu um grande impacto na formação familiar, uma vez que o conceito de família passou por substanciais transformações, influenciando diretamente na criação de um segundo princípio, o princípio da pluralidade das entidades familiares.

Revista de Direito de Família e Sucessão | e-ISSN: 2526-0227 | Maranhão | v. 3 | n. 2 | p. 17 - 35 | Jul/Dez. 2017. 
Trata-se de uma transição paradigmática ocorrida no seio do Direito de Família, que estava assentado no matrimônio, ao ponto em que a família advinha do casamento, exclusivamente. Com o advento da CF/1988, expandiu-se o conceito de família para relações que não estivessem pautadas no matrimônio, à luz do art. 226 da CF/1988, passando a ter proteção não mais tão somente a família advinda do casamento, mas qualquer outro tipo de expressão afetiva, como a união estável e a família monoparental.(FARAIS, ROSENVALD, 2016).

A família é objeto de uma nítida transição, deixa de ser compreendida tão somente como um núcleo econômico e reprodutivo, e passa a ser encarada como uma manifestação de afeto e apoio mútuo. Surgem, de forma consequencial, novos arranjos familiares, à luz da sobreposição da dignidade da pessoa humana sobre o patrimônio, do afeto sobre o casamento.

Sobre a temática, vale analisar o que Lôbo (2010, p.64) preleciona:

A família recuperou a função que, por certo, esteve nas suas origens mais remotas: a de grupo unido por desejos e laços afetivos, em comunhão de vida. O princípio jurídico da afetividade faz despontar a igualdade entre irmãos biológicos e adotivos e o respeito a seus direitos fundamentais, além do forte sentimento de solidariedade recíproca, que não pode ser perturbada pelo prevalecimento de interesses patrimoniais. É o salto, à frente, da pessoa humana nas relações familiares.

O autor destaca a relevância do princípio jurídico da afetividade, este como potencial garantidor dos direitos fundamentais dos indivíduos, através da eliminação de desigualdades pautadas em critérios ilegítimos, fulcrados em interesses patrimoniais. Seria através do princípio em análise, que o instituto da família consegue, finalmente, recuperar as suas origens, que estão baseadas na união por sentimetos, afetividade e não apenas por laços consanguíneos.

Ademais, é cediço que o princípio da afetividade é reconhecido também pela jurisprudência pátria como elemento legitimador de efeitos jurídicos às famílias estruturadas no afeto, sublimando conceitos conservadores sobre o instituto da família, como o de que esta é fundada no casamento com fins de procriação. 
É neste novo panorama valorativo que ganha destaque e reconhecimento a paternidade socioafetiva, em outros termos, o vínculo de paternidade criado a partir do afeto, descartando-se a ideia de que este vínculo só poderia advir de laços consanguíneos.

Reconhecimento este consubstanciado em vários enunciados das Jornadas de Direito Civil, destacando-se o teor dos dois principais. Trata-se, inicialmente, do enunciado $n^{\circ} 103$ da I Jornada de Direito Civil, que ressalta a figura do parentesco advindo da paternidade socioafetiva, fulcrada na posse do estado de filho, que possui três critérios para a sua configuração: tratamento (relacionamento entre pai e filho, por exemplo), fama (a relação entre os indivíduos possui um caráter público, externo) e nome (uso do sobrenome), o último com uma configuração mais complicada, tendo a necessidade de sua configuração relativizada por certos doutrinadores, como Nelson Ronsevald.

103 - Art. 1.593: o Código Civil reconhece, no art. 1.593, outras espécies de parentesco civil além daquele decorrente da adoção, acolhendo, assim, a noção de que há também parentesco civil no vínculo parental proveniente quer das técnicas de reprodução assistida heteróloga relativamente ao pai (ou mãe) que não contribuiu com seu material fecundante, quer da paternidade sócio-afetiva, fundada na posse do estado de filho. (CJF, 2002).

Ademais, destaca-se um segundo enunciado, o de $n^{\circ} 519$, da V Jornada de Direito Civil, que ressalta que o reconhecimento judicial do parentesco em decorrência da socioafetividade necessita ocorrer a partir do reconhecimento da posse do estado de filho, gerando efeitos pessoais e patrimoniais.

519 - Art. 1.593: O reconhecimento judicial do vínculo de parentesco em virtude de socioafetividade deve ocorrer a partir da relação entre pai(s) e filho(s), com base na posse do estado de filho, para que produza efeitos pessoais e patrimoniais. (CJF, 2012).

Neste sentido, é importante frisar que o citado enunciado atesta que há a produção de efeitos pessoais e patrimoniais decorrentes de uma paternidade sócio-afetiva, o que possui uma nítida relação com a problemática apresentada, uma vez que há uma série de institutos do 
Direito de Família a serem pensados a partir da relação entre a criança e cônjuge divorciado, como direito de visitas, pensão alimentícia, guarda, entre outros, que serão analisados e discutidos posteriormente, em momento oportuno.

Pôde-se analisar, na presente seção, a relação do fenômeno da constitucionalização do Direito Civil com a valorização da afetividade nas relações familiares, com o princípio da afetividade, proporcionando uma pluralidade de arranjos familiares. Ademais, ainda como um produto do citado fenômeno, pôde-se ressaltar também o parentesco advindo do afeto, o seu reconhecimento no novo panorama do Direito Civil, a paternidade sócio-afetiva.

A importância de tratar dos citados institutos está na utilização de tais informações na análise da problemática apresentada ao início, que está marcada pelo instituto da Multiparentalidade, que será apresentado e analisado na próxima seção.

\subsection{MULTIPARENTALIDADE: UMA EXPRESSÃO DA IGUALDADE ENTRE O PARENTESCO BIOLÓGICO E SOCIOAFETIVO}

O instituto da multiparentalidade ou pluriparentalidade consiste na possibilidade de um indivíduo possuir mais de um pai e/ou mais de uma mãe, de forma simultânea. Está pautada na ideia de que a filiação sócio-afetiva não pode eliminar a biológica, tendo em vista que possuem critérios diferentes para a sua configuração (ROSENVALD; FARIAS, 2016).

O presente instituto possui sua existência defendida por Belmiro Pedro Welter, criador da Teoria Tridimensional do Direito de Família, que sustenta a existência humana fulcrada em três mundos, o mundo genético, afetivo e ontológico. Os dois primeiros autoexplicativos, diante do que já foi analisado anteriormente. O mundo ontológico, por sua vez, consiste no modo que indivíduo se relaciona consigo mesmo.

Com base nos citados três mundos, o autor defende que o ser humano é biológico, afetivo e ontológico, simultaneamente, o que desencadearia a possibilidade de três vínculos paternos e/ou maternos. Defendendo-se, ainda, a igualdade entre as paternidades, não havendo 
a sobreposição de uma sobre a outra. (ROSENVALD; FARIAS, 2016). Teoria a qual esta pesquisa se filia.

Ana Carolina Harmatiuk Matos e Paula Aranha Hapner, ambas pesquisadoras da Universidade Federal do Paraná, em seu artigo intitulado Multiparentalidade: uma abordagem a partir das decisões nacionais, publicado no periódico Civilística (2016), destacam que o instituto da multiparentalidade atesta uma transição de perspectiva a favor do reconhecimento da possibilidade de filiações plurais.

Destacando essa transição, as autoras sustentam a existência de três momentos. O primeiro seria decisões judiciais que consideravam impossível juridicamente o pedido, quando se buscava o reconhecimento judicial da multiparentalidade. O segundo momento seria o de defender a sobreposição da filiação biológica em face da sócio-afetiva. E por fim, o terceiro momento seria o reconhecimento da igualdade de ambas as filiações, o que possui base constitucional diante do princípio da igualdade entre os filhos, exposto no art. 227, $\S 6^{\circ}$ da $\mathrm{CF} / 1988$.

Nelson Rosenvald e Cristiano Farias defendem a admissão do presente instituto no Direito de Família, mesmo que esta admissão represente um entendimento contra majoritário em relação ao entendimento jurisprudencial contemporâneo.

\footnotetext{
A posição majoritária em nossa jurisprudência é no sentido de negar cabimento à multiparentalidade como um direito indiscriminado, esclarecendo que a filiação será determinada através de um, ou de outro, critério, a depender do caso concreto. [...]

Contudo, em nossa visão, a pluriparentalidade pode ser admitida em casos nos quais se demonstre a convivência simultânea, ou sucessiva de alguém com duas outras pessoas que se apresentem, efetivamente, como pais ou mães. Seriam casos nos quais alguém possui, efetivamente, sob o prisma da construção parental, dois pais e/ou duas mães.

Imagina-se a pessoa que convive com o pai biológico, de quem a mãe já se separou, mas que mantém convivência simultânea, ou sucessiva, com outro homem, que, igualmente, exerce o papel de pai, em concomitância. (Rosenvald; Farias, 2016, p. 619).
}

A partir do que foi ressaltado no presente tópico, fazendo-se relação com o que foi apresentado no presente artigo, resta nítida uma correlação que pode ser levantada, 
considerando a problemática apresentada ao início do artigo: duas relações em relação a criança, uma com seu pai biológico e outra com o ex-cônjuge, quem poderia ser considerado(a) um pai ou mãe sócio-afetiva.

Destaca-se, nitidamente, que é possível se defender a aplicação da multiparentalidade à problemática citada, destacando-se a configuração deste instituto como um produto da Constitucionalização do Direito Civil, no sentido de que ele assume o papel de uma consubstanciação da valorização do afeto, da aceitação de múltiplas formas de vida, da prevalência da solidariedade, igualdade e dignidade da pessoa humana.

Apresentados os fundamentos jurídicos aptos a fundamentar a análise proposta pelo presente artigo, passar-se-á a realizar o estudo do problemática à luz dos institutos e fenômenos indicados e estudados ao longo do presente artigo, a fim de se buscar a análise mais adequada para a questão destacada.

\section{O RECONHECIMENTO DA MULTIPARENTALIDADE EM CASOS DE PATERNIDADE SOCIOAFETIVA SEGUIDA DE DIVÓRCIO}

A partir do que foi exposto no desenvolvimento do presente artigo, pôde-se observar que o Direito Civil, nele o Direito de Família, foi, e ainda é, objeto de um processo de transição, chamado de Constitucionalização do Direito Civil, processo este que aproximou as normas civilistas do Direito Constitucional, da Constituição. Destacando-se que foi a “Constituição cidadã”, Constituição de 1988, que foi o maior agente de impacto nas normas civilistas, proporcionando uma transição paradigmática de valores voltados do ter para o ser, promovendo-se a dignidade da pessoa humana, solidariedade e igualdade.

O Direito de Família não ficou fora desse processo de transição, muito pelo contrário, foi fortemente impactado, principalmente em relação ao conceito de Família. Esta deixou de ser apenas o núcleo formado por laços biológicos, conforme explicado anteriormente, sendo que o princípio da afetividade foi absorvido pelo Direito Civil Constitucional, dando-se prevalência ao aspecto factual no âmbito familiar. Os fatos, o afeto, não poderiam ser

Revista de Direito de Família e Sucessão | e-ISSN: 2526-0227 | Maranhão | v. 3 | n. 2 | p. 17 - 35 | Jul/Dez. 2017. 
menosprezados em função do laço sanguíneo, proporcionando-se, assim, uma pluralidade de entidades familiares.

Ressalta-se que o processo de Constitucionalização do Direito Civil, entre outras consequências, gerou uma ressignificação da Família, podendo esta ser formada também por laços afetivos, como é o caso da paternidade sócio-afetiva, que se encaixa perfeitamente na problemática apresentada.

O ex-cônjuge e a criança, cumprindo os requisitos para esta constatação, possuem uma relação de afeto, que não deixará de existir simplesmente porque o indivíduo não mais está casado com um dos pais biológicos da criança. O Direito Civil, até mesmo resguardando o melhor interesse da criança, não poderia compactuar com o apagamento de uma relação de afeto existente entre dois sujeitos devido a um divórcio.

Neste caso, entende-se que ex-cônjuge pode buscar o reconhecimento de uma paternidade sócio-afetiva em relação a criança, quem possui os requisitos legais (posse de estado de filho) para ser considerado seu filho.

Entretanto, a problemática citada não é resolvida apenas pela constatação da possibilidade do reconhecimento da paternidade sócio-afetiva do ex-cônjuge. Deve-se atentar para o fato de que a criança já possui uma filiação biológica, supondo que estes pais nunca deixaram de participar da vida de seu filho.

Surge, assim, uma indagação quanto à possibilidade de se conciliar duas ou mais filiações. A partir do que foi explanado no presente artigo, a presente problemática analisada estaria inserida no instituto da Multiparentalidade, uma vez que a criança teria um vínculo biológico, assim como preenche os requisitos para ter uma filiação sócio-afetiva, em relação ao ex-cônjuge.

Defende-se que não se pode sustentar a prevalência de uma espécie de filiação sobre a outra, ou seja, a filiação biológica e a socioafetiva não se excluem, uma vez que se deve levar em consideração o princípio da igualdade entre filhos, consubstanciado na magna carta, conforme já destacado. Assim, tratando-se da problemática em análise, não se pode fazer distinção entre filho biológico e filho sócio-afetivo, tampouco em relação à paternidade e maternidade.

Revista de Direito de Família e Sucessão | e-ISSN: 2526-0227 | Maranhão | v. 3 | n. 2 | p. 17 - 35 | Jul/Dez. 2017. 
Desta forma, a melhor solução diante da problemática apresentada é a convivência entre a filiação biológica e a filiação sócio-afetiva, convivência esta chamada de Multiparentalidade.

Ainda em relação à análise da problemática apresentada, deve-se acrescentar um elemento à discussão, os direitos que o ex-cônjuge possuiria em relação a criança, ao ser considerado pai ou mãe sócio-afetiva do mesmo, em regime de Multiparentalidade.

O ex-cônjuge, ao se tornar pai ou mãe sócio-afetiva da criança, evidentemente, possuirá direitos em relação ao menor, assim como este também terá direitos resguardados em relação ao ex-cônjuge. Pode-se vislumbrar efeitos jurídicos decorrentes do citado parentesco no âmbito patrimonial, assim como na esfera não patrimonial.

No âmbito não patrimonial, destaca-se a inserção do nome da mãe ou pai sócio-afetivo no nome do menor. Trata-se do primeiro direito identificado que o ex-cônjuge poderia exercer em face de seu filho. Sobre esta possibilidade, destaca-se o entendimento jurisprudencial sobre o tema, que reconheceu o cabimento da Multiparentalidade, esta gerando efeitos no âmbito do direito ao nome.

MATERNIDADE SOCIOAFETIVA. Preservação da maternidade biológica - Respeito à memória da mãe biológica, falecida em decorrência do parto, e de sua família - Enteado criado como filho desde dois anos de idade Filiação socioafetiva que tem amparo no art. 1.593 do Código Civil e decorre da posse do estado de filho, fruto de longa e estável convivência, aliado ao afeto e considerações mútuos, e sua manifestação pública, de forma a não deixar dúvida, a quem não conhece, de que se trata de parentes A formação da família moderna não consanguínea tem sua base na afetividade e nos princípios da dignidade da pessoa humana e da solidariedade - Recurso provido. (TJ/SP, Ac. Unân. $1^{\text {a }}$ Câmara de Direito Privado, Ap. Cív. 6422-26.2011.8.26.0286 - Comarca de Itu, Rel. Des. Alcides Leopoldo e Silva Júnior, j. 15.08.2012).

Ainda que minoritária, pode-se identificar uma linha jurisprudencial que considera possível a configuração da multiparentalidade, destacando-se a citada decisão proferida pelo Tribunal de Justiça de São Paulo, de 2012, que reconhece o direito de se ter duas mães e um pai, diante do caráter fático da convivência entre os indivíduos envolvidos. 
No citado caso, reconheceu-se o instituto da multiparentalidade, entretanto este apenas gerou efeito jurídico no que concerne à inserção do nome da mãe sócio-afetiva e não os efeitos patrimoniais.

Entretanto, apesar do Supremo Tribunal Federal admitir a possibilidade do reconhecimento da Multiparentalidade, ainda se enfrenta dificuldades no reconhecimento dos seus efeitos jurídicos, como pode ser observado na jurisprudência abaixo, própria do Tribunal do Rio Grande do Sul, que nega a alteração do registro civil de uma criança para a inclusão do nome de dois pais. Chama-se atenção para a data do julgado, 16 de agosto de 2017.

\begin{abstract}
APELAÇÃO. DIREITO CIVIL FAMÍLIA. AÇÃO DE RECONHECIMENTO DE PATERNIDADE. ANULAÇÃO DE REGISTRO CIVIL. MULTIPARENTALIDADE. IMPOSSIBILIDADE.

Em que pese tenha o STF, ao analisar a Repercussão Geral 622, admitido a possibilidade do reconhecimento da multiparentalidade, a alteração no registro civil de uma criança constando o nome de dois pais é situação não prevista em lei, o que impossibilita o reconhecimento da pretensão recursal. RECURSO DESPROVIDO. (Apelação Cível No 70073977670, Sétima Câmara Cível, Tribunal de Justiça do RS, Relator: Liselena Schifino Robles Ribeiro, Julgado em 16/08/2017).
\end{abstract}

Ao se destacar o instituto da multiparentalidade é evidente as incertezas sobre a aplicação de inúmeros efeitos jurídicos decorrentes do reconhecimento de um laço de parentesco, como: exercício do poder familiar, alimentos, possibilidade de emancipação, guarda e regulamentação de visitas.

Com base no princípio da igualdade entre os filhos, com previsão constitucional, infere-se que seria inconstitucional sustentar qualquer tipo de diferença entre o filho biológico e o filho socioafetivo, inconstitucionalidade esta que se estende à paternidade sócio-afetiva e biológica, o que repercute diretamente na discussão sobre os direitos do pai sociafetivo em relação a seu filho, quando em regime de multiparentalidade.

Defende-se, a partir do que foi exposto e analisado na presente pesquisa, que sustentar a hipótese de uma paternidade com direitos limitados seria inconstitucional, uma vez que estaria criando a figura do “meio pai”, o que é vedado no ordenamento jurídico brasileiro.

Revista de Direito de Família e Sucessão | e-ISSN: 2526-0227 | Maranhão | v. 3 | n. 2 | p. 17 - 35 | Jul/Dez. 2017. 
Desta forma, diante do reconhecimento do ex-cônjuge como pai sócio-afetivo da criança, deve-se garantir todos os direitos inerentes à paternidade ou maternidade, caso contrário se estaria sustentando uma inconstitucionalidade. À luz do caso apresentado, defende-se que o ex-cônjuge deve ter todos os direitos e deveres inerentes à paternidade resguardados em relação à criança, como inclusão do seu sobrenome no nome do filho, exercício do poder familiar, prestação de alimentos, guarda e regulamentação de visitas, entre outros. Ou seja, direito não patrimoniais e patrimoniais.

Em relação aos últimos, destaca-se um julgado do Tribunal de Santa Catarina, que reconhece os efeitos patrimoniais decorrentes do instituto da Multiparentalidade:

\begin{abstract}
APELAÇÃO CÍVEL. AÇÃO DE INVESTIGAÇÃO DE PATERNIDADE C/C ALIMENTOS. EXTINÇÃO DO FEITO, SEM RESOLUÇÃO DO MÉRITO PELA IMPOSSIBILIDADE JURÍDICA DO PEDIDO E ILEGITIMIDADE DA REPRESENTANTE DA AUTORA.

[...]. EVIDENCIADO O INTERESSE DE AGIR DA FILHA A FIM DE VER ESCLARECIDA SUA ASCENDÊNCIA BIOLÓGICA. EXISTÊNCIA DE LAÇOS AFETIVOS COM O PAI REGISTRAL QUE NÃO SE AFIGURA OBSTÁCULO INTRANSPONÍVEL AO RECONHECIMENTO DA PATERNIDADE BIOLÓGICA. POSSIBILIDADE DO REGISTRO CIVIL DA MULTIPARENTALIDADE. PRECEDENTE UNÂNIME DO GRUPO DE CÂMARAS DE DIREITO CIVIL DESTA CORTE. INTERESSE DE AGIR CONFIGURADO. NECESSIDADE DE RETORNO DOS AUTOS A ORIGEM PARA INSTRUÇÃO PROCESSUAL. SENTENÇA CASSADA. RECURSO CONHECIDO E PROVIDO.

- "A preexistência da paternidade socioafetiva não impede a declaração judicial da paternidade biológica, com todas as consequências dela decorrentes, inclusive as de natureza patrimonial." (TJSC, Embargos Infringentes n. 2014.084742-5, j. 09-03-2016, grifo nosso).
\end{abstract}

Todavia, deve-se instituir ponderações no exercício de tais direitos, principalmente, quando o exercício dos direitos e deveres relacionados à paternidade e maternidade possam prejudicar a criança ou o adolescente. Assim, o exercício dos direitos do ex-cônjuge, enquanto mãe ou pai sócio-afetivo, deve sofrer ponderações à luz do melhor interesse da criança, 
entretanto não só os direitos do ex-cônjuge, mas também os direitos inerentes à figura de pai e mãe biológicos.

Assim, a partir do presente artigo, pode-se defender que o ex-cônjuge possui direitos em relação à criança, direitos estes inerentes à paternidade/maternidade, que não podem ser considerados de forma absoluta, assim como nenhum direito próprio aos pais biológicos.

Os citados direitos e deveres inerentes aos dois pais biológicos e ao pai sócio-afetivo devem sofrer ponderações à luz do princípio do melhor interesse da criança. Destaca-se, entretanto, que a análise daquilo que é o ideal para o menor é feita de forma casuística. Sendo um dever da família, da sociedade e do Estado assegurar à esta criança os seus direitos constitucionais, conforme previsão do art. 227 da Constituição Federal, transcrito abaixo:

Art. 227. É dever da família, da sociedade e do Estado assegurar à criança, ao adolescente e ao jovem, com absoluta prioridade, o direito à vida, à saúde, à alimentação, à educação, ao lazer, à profissionalização, à cultura, à dignidade, ao respeito, à liberdade e à convivência familiar e comunitária, além de colocá-los a salvo de toda forma de negligência, discriminação, exploração, violência, crueldade e opressão.

É o conjunto de tais direitos que forma aquilo que é entendido como o melhor interesse da criança. Sendo tutelado não apenas pela Constituição Federal, mas também pela Convenção Internacional dos Direitos da Criança, em seu art. $3^{\circ}$.

Desta forma, deve-se chegar a um consenso sobre a aplicação de tais direitos à luz do que for melhor para o menor. Assim, concluindo a análise à problemática apresentada, defende-se que ex-cônjuge possuiria direitos em relação à criança, todos os direitos, assim como deveres, inerentes à paternidade/maternidade.

\section{CONSIDERAÇÕES FINAIS}

Conforme destacado ao início do presente artigo, o objeto de estudo deste ensaio paira sobre a aplicação do instituto da Multiparentalidade no caso marcado por um vínculo sócioafetivo de um dos cônjuges com a criança fruto de outro relacionamento de seu parceiro, 
seguido da dissolução do casamento. Buscou-se analisar a razoabilidade da aplicação da Multiparentalidade neste panorama fático.

Para tanto, em um primeiro momento, iniciou-se a análise jurídica através do estudo do fenômeno da Constitucionalização do Direito Civil, que marcou uma transição paradigmática valorativa, em que o ser passa a ter prevalência sobre o ter, fazendo com que o Direito Civil passe a ser permeado, principalmente, pelos princípios da igualdade (art. $5^{\circ} \mathrm{CF}$ ) e da solidariedade social (art. $3^{\circ}, \mathrm{I}, \mathrm{CF}$ ).

Tal fenômeno causa impactos diretos, também, ao Direito de Família, nitidamente, a partir da noção de inclusão materializada no art. 226 da Constituição Federal. Discutiu-se que a família não advém mais tão somente do casamento, considerando-se a relevância do afeto na formação de entidades familiares.

Ainda sobre afeto, tratou-se de dois princípios que possuem nítida relação com o fenômeno da Constitucionalização do Direito Civil, eis o princípio da afetividade e da pluralidade das entidades familiares, destacando-se o reconhecimento da filiação sócioafetiva.

Foi com base na citada análise teórica e jurídica que se passou a analisar o instituto da Multiparentalidade, e posteriormente a possibilidade de sua aplicação à problemática apresentada. A Pluriparentalidade, como também é chamado o instituto em questão, como um instrumento que visa resguardar as múltiplas formas de vida, colocando em paridade a filiação biológica e a sócio-afetiva, ao permitir a convivência dos dois vínculos em relação a uma pessoa.

Por fim, analisou-se o cabimento da aplicação do instituto da Multiparentalidade à problemática apresentada, que foi composta por quatro indivíduos: os dois pais biológicos, o ex-cônjuge e a criança. Passou-se a analisar se o referido instituto poderia ser reconhecido no caso do então cônjuge possuir um vínculo sócio-afetivo com o seu então enteado, entretanto, após o seu divórcio do pai biológico da criança.

Analisando-se os fundamentos ressaltados ao longo do artigo, principalmente a necessidade de se reconhecer o afeto como um elemento de importância na formação de 
entidades familiares, entendeu-se por defender a aplicação do instituto da Multiparentalidade no panorama problemático apresentado, seguido dos seus efeitos jurídicos tanto no âmbito patrimonial como não patrimonial.

Inclusive, no que concerne aos efeitos jurídicos, realizou-se uma análise jurisprudencial, em que se pôde extrair que é entendimento minoritário ainda o reconhecimento da Multiparentalidade e quando reconhecida, o principal efeito jurídico constatado é o direito ao nome. Apesar de ser minoria, apresentou-se, também, um julgado em que o Tribunal de Santa Catarina reconhece os efeitos patrimoniais decorrentes da Multiparentalidade.

Em linhas de conclusão, considerando a problemática que enseja o presente estudo, defende-se a aplicação do instituto da Multiparentalidade mesmo após a dissolução do casamento, tendo em vista que o afeto entre estes indivíduos (ex-cônjuge e a criança) precisa ser considerado e não deixará de existir em face de um divórcio. Ressalva-se, entretanto, que esta análise está pautada na consideração de que todos os requisitos para uma filiação sócioafetiva foram cumpridos.

Desta forma, defende-se o reconhecimento do instituto da Multiparentalidade, à luz de todos os direitos e deveres inerentes à paternidade e maternidade, considerando o melhor interesse da criança.

\section{REFERÊNCIAS}

BRASIL. Constituição (1988). Constituição da República Federativa do Brasil. Brasília, DF: Senado Federal, 1988.

CARDOSO, Simone Tassinari. Notas sobre parentalidade biológica e socioafetiva: do direito civil moderno ao contemporâneo. Civilística. A. 5. N. 1. 2016

CONSELHO DA JUSTIÇA FEDERAL. Enunciado n 103. I Jornada de Direito Civil, 2002. Enunciado n 519. V Jornada de Direito Civil, 2012.

FARIAS, Cristiano Chaves de; ROSENVALD, Nelson. Curso de Direito Civil: Famílias. V.6. 8 ed. Salvador: JusPodivm, 2016.

LÔBO, Paulo. Direito Civil: famílias. $3^{\text {a }}$ ed. São Paulo: Saraiva, 2010.

Revista de Direito de Família e Sucessão | e-ISSN: 2526-0227 | Maranhão | v. 3 | n. 2 | p. 17 - 35 | Jul/Dez. 2017. 
MATOS, Ana Carla Harmatiuk; HAPNER, Paula Aranha. Multiparentalidade: uma abordagem a partir das decisões nacionais. Civilística. A. 5. N. 2. 2016.

TARTUCE, Flávio. Direito Civil: Direito de Família. V.5. 12 ed. Rio de Janeiro: Forense, 2017.

VENOSA, Sílvio de Salvo. Direito Civil: Parte Geral. V.1. 15 ed. São Paulo: Atlas, 2015. 